\title{
NÍVEIS DE SOMBREAMENTO NO DESENVOLVIMENTO DE MUDAS DE Hymenaea courbaril var. Stilbocarpa
}

\author{
Maximiliano Kawahata Pagliarini ${ }^{1 *}$, Erica Rodrigues Moreira ${ }^{2}$, Flávia Aparecida de \\ Carvalho Mariano Nasser ${ }^{3}$, Veridiana Zocoler de Mendonça ${ }^{4}$, Regina Maria Monteiro de \\ Castilho $^{5}$
}

\footnotetext{
${ }^{1}$ Técnico em Agropecuária, Doutor em Agronomia, Universidade Federal da Grande Dourados, Fazenda Experimental de Ciências Agrárias, Dourados - MS. E-mail: mpagliarini@ufgd.edu.br

${ }^{2}$ Pós-doutoranda, Programa Nacional de Pós-Doutorado (PNPD), Universidade Federal de Tocantins, Campus de Gurupi - TO.

${ }^{3}$ Pós-doutoranda em Agronomia - Horticultura, Universidade Estadual Paulista (UNESP), Faculdade de Ciências Agronômicas, Campus de Botucatu - SP.

${ }^{4}$ Doutora em Agronomia - Energia na Agricultura, Universidade Estadual Paulista (UNESP), Faculdade de Ciências Agronômicas, Campus de Botucatu - SP.

${ }_{5}^{5}$ Professora Assistente Doutora, Departamento de Fitotecnia, Tecnologia de Alimentos e Sócio Economia, Universidade Estadual Paulista (UNESP), Faculdade de Engenharia, Campus de Ilha Solteira - SP.
}

RESUMO: Cada espécie tem exigências próprias para o seu desenvolvimento. Luz, água, temperatura são alguns dos elementos abióticos que influenciam no desenvolvimento das plantas. A luz é importante no desenvolvimento vegetativo por influir, entre outros processos, na taxa de fotossíntese; a intensidade, qualidade, duração e periodicidade da luz agem tanto quantitativa como qualitativamente no incremento da planta. Objetivou-se testar diferentes níveis de sombreamento no desenvolvimento de mudas de jatobá (Hymenaea courbaril var. Stilbocarpa). O experimento foi realizado em área aberta sendo as mudas produzidas em casa de vegetação do tipo Pad \& Fan e transplantadas para sacos pretos de 5 litros aos 20 dias após a semeadura usando-se mistura de solo e composto orgânico (1:1) como substrato. $\mathrm{O}$ delineamento experimental foi inteiramente casualizado com quatro tratamentos e 13 repetições cada, uma planta por parcela. Os tratamentos foram: $\mathrm{T} 1=$ Pleno sol; $\mathrm{T} 2=$ Tela de sombreamento $30 \% ; \mathrm{T} 3=$ Tela de sombreamento 50\%; $\mathrm{T} 4=$ Tela de manipulação de espectro de luz ChromatiNet ${ }^{\oplus}$ vermelho $30 \%$. As telas foram fixadas em telados de madeira de dimensões $1 \times 1 \times 1 \mathrm{~m}$ (altura $\mathrm{x}$ largura $\mathrm{x}$ comprimento). As características analisadas foram: altura das plantas, diâmetro médio do caule das plantas, teor de clorofila das folhas, relação altura de planta e diâmetro de caule, área foliar e massa fresca e seca de raiz e parte aérea. As melhores mudas de jatobá (Hymenaea courbaril var. Stilbocarpa) foram produzidas em sombreamento de 30 e $50 \%$ em 84 dias após o transplante.

Palavras-chave: Telas de sombreamento. Espectro de luz. ChromatiNet ${ }^{\oplus}$ vermelho.

\section{SHADING LEVELS IN Hymenaea courbaril var. Stilbocarpa SEEDLINGS DEVELOPMENT}

Cultura Agronômica, Ilha Solteira, v.26, n.3, p.330-346, 2017 


\begin{abstract}
Each species has its own development requirements. Light, water, temperature are some of the abiotic elements that influence plants development. Light is important in vegetative development because it influences, among other processes, the rate of photosynthesis; intensity, quality, duration and periodicity of light act both quantitatively and qualitatively in plant increment. The objective was to test different shading levels in Hymenaea courbaril var. Stilbocarpa seedlings development. The experiment was conducted in an open area and seedlings were grown in a Pad \& Fan greenhouse type transplanted to 5 L black bags at 20 days after sowing filled with a mixture of soil and organic compost (1:1) as substrate. The experimental design was completely randomized with four treatments and 13 replicates each, one plant per plot. The treatments were: $\mathrm{T} 1=$ Full sun, $\mathrm{T} 2=$ net shade $30 \%, \mathrm{~T} 3=$ net shade 50\%, T4 = light spectrum manipulation net Chromatinet ${ }^{\circledR}$ Red 30\%. The shading nets were fixed on woodens dimensions 1x1x1 m (height $\mathrm{x}$ width $\mathrm{x}$ length). The characteristics analysed were: plant height, stem diameter, leaves chlorophyll content, plant height and stem diameter ratio, leaf area and fresh and dry weight of roots and shoots. The best Hymenaea courbaril var. Stilbocarpa seedlings were obtained in shading from $30 \%$ and $50 \%$ at 84 days after transplant.
\end{abstract}

Key words: Net shades. Light spectrum. Red ChromatiNet ${ }^{\circledR}$.

\title{
INTRODUÇÃO
}

Hymenaea courbaril var. Stilbocarpa, popularmente conhecida por jatobá da mata, é uma espécie nativa do país pertence à família Fabaceae que ocorre do Piauí ao norte do Paraná nas florestas semidecíduas podendo alcançar de 15 a $25 \mathrm{~m}$. Possui tronco reto, cilíndrico de até $1 \mathrm{~m}$ de diâmetro com copa alta, muito ramificada e frondosa (MACHADO et al. 2006). Segundo Tigre (1976) e Lorenzi (1998), é recomendada para a composição de reflorestamento heterogêneo; já para Machado et al. (2006), por ter uma floração pouco vistosa e fornecer excelente sombra, pode ser utilizada na arborização de praças e parques.

Dentro de um programa de produção de mudas, além do conhecimento da importância da espécie é importante conhecer aspectos fisiológicos inerentes a cada uma para permitir planejamento da utilização dos espaços, e escalonamento da produção (OLIVEIRA et al. 1989).

Cada espécie tem exigências próprias para o seu desenvolvimento. A luz, por exemplo, é importante no crescimento da planta por influenciar, entre outros processos, na taxa de fotossíntese; a intensidade, qualidade, duração e periodicidade da luz influenciam tanto quantitativa como qualitativamente no desenvolvimento da planta (KRAMER; KOZLOWSKI, 1972). Em relação ao jatobá, Lorenzi (1998) classifica a espécie como sendo oportunista que pela definição de Viana (1989) são plantas com sementes que não requerem muita luminosidade para germinar, com plântulas que sobrevivem à sombra, mas que dependem de aberturas do dossel para atingir o estágio reprodutivo. Neste aspecto, tem-

Cultura Agronômica, Ilha Solteira, v.26, n.3, p.330-346, 2017 
se utilizado o método de sombreamento artificial para avaliar o comportamento das mudas de espécies florestais quanto à intensidade luminosa.

Alguns estudos têm evidenciado a plasticidade fisiológica de espécies vegetais em relação à radiação fotossinteticamente ativa disponível por meio de avaliações de crescimento inicial em relação a diferentes níveis de sombreamento (ALMEIDA et al. 2005a).

Nesse contexto, a adaptação das plantas ao ambiente de luz depende do ajuste de seu aparelho fotossintético, de modo que a luminosidade ambiental seja utilizada de maneira mais eficiente possível, sendo, as respostas dessa adaptação refletidas no crescimento global da planta. Assim, a eficiência do crescimento pode estar relacionada com a habilidade de adaptação das plântulas e as condições de intensidade luminosa do ambiente (FANTI; PEREZ, 2003).

Novas tecnologias na utilização de telas estão sendo empregadas em substituição às malhas de sombreamento de cor preta cujo objetivo principal é proteger as plantas da radiação. Esses materiais de polietileno de baixa densidade (PEBD) são de várias colorações (azul, vermelho, amarelo, cinza) com funções específicas na sua utilização (HUERTAS, 2006). A malha vermelha, por exemplo, muda o espectro da luz que a atravessa, reduzindo as ondas azuis, verdes e amarelas e acrescentando as ondas vermelha e vermelha-distante. Como consequência deste processo as plantas cobertas com malhas vermelhas podem desenvolver-se mais rapidamente; a superfície das folhas pode ser maior; as hastes mais compridas e em geral o volume da folhagem pode aumentar (POLYSACK INDÚSTRIAS, 2011).

Dessa forma, o objetivo do presente trabalho foi avaliar diferentes níveis de sombreamento no desenvolvimento de mudas de jatobá da mata.

\section{MATERIAL E MÉTODOS}

O experimento foi realizado na UNESP, Campus de Ilha Solteira (lat. 20²5'28' S, long. 51 ${ }^{\circ} 21^{\prime} 15^{\prime \prime} \mathrm{W}, 354 \mathrm{~m}$ de alt.) em área aberta. As mudas foram produzidas em casa de vegetação do tipo Pad \& Fan de acordo com recomendações de Pagliarini et al. (2016). Aos 20 dias após a semeadura, quando as mudas apresentaram duas folhas verdadeiras, as mudas foram transplantadas em sacos pretos de 5 litros, preenchidos com mistura de solo e composto orgânico $(1: 1, \mathrm{v}: \mathrm{v})$.

O solo utilizado foi Latossolo Vermelho Distroférrico (EMBRAPA, 2013) retirado da camada de 0 - $20 \mathrm{~cm}$ da Fazenda Experimental da UNESP, Campus de Ilha Solteira - SP localizada no município de Selvíria - MS, enquanto que o composto orgânico foi feito a partir de folhas de grama batatais, adicionado esterco bovino curtido, e posto para decompor por 90 dias.

Cultura Agronômica, Ilha Solteira, v.26, n.3, p.330-346, 2017 
Foram confeccionados telados de madeira de dimensões $1 \mathrm{x} 1 \mathrm{x} 1 \mathrm{~m}$ (altura $\mathrm{x}$ largura $\mathrm{x}$ comprimento) no qual as telas foram fixadas. A irrigação foi feita de forma manual e diariamente até que alcançasse a capacidade de campo do substrato. Para que a temperatura do concreto não interferisse no desenvolvimento das mudas, as mesmas foram alocadas sobre uma camada de tijolos e não houve adição de adubos químicos.

As mudas foram submetidas a quatro níveis de sombreamento: $\mathrm{T} 1=$ Pleno sol; $\mathrm{T} 2=$ Tela de sombreamento 30\%; T3 = Tela de sombreamento 50\%; T4 = Tela de manipulação de espectro de luz ChromatiNet ${ }^{\circledR}$ Vermelho 30\%. O delineamento experimental foi inteiramente casualizado com 4 tratamentos e 13 repetições, uma planta por parcela.

As avaliações foram realizadas no dia do transplante, 14, 28, 42, 56, 70 e 84 dias após para as seguintes características: altura das plantas $(\mathrm{cm})$ : medida da superfície do substrato até a gema apical com uma régua graduada; diâmetro médio do caule das plantas $(\mathrm{mm})$ : medido rente ao substrato com um paquímetro digital; teor de clorofila das folhas: medido com auxílio de clorofilômetro (Minolta SPAD-5010), cujas leituras foram tomadas em três folhas: uma no ápice, parte média e inferior de cada planta, obtendo-se valores médios convertidos para mg $100 \mathrm{~cm}^{-2}$ a partir da equação proposta por Furlani Junior et al. (1996): $\mathrm{Y}=0,0996 \mathrm{X}-0,152$; relação altura de planta e diâmetro de caule: calculado através da divisão das médias de alturas de plantas pelos diâmetros de caule. Aos 84 dias após o transplante foram avaliados: área foliar adotando-se o método de pesagem de discos foliares proposto por Mielke (1995), utilizando-se um vazador com área conhecida $\left(6,44 \mathrm{~cm}^{2}\right)$, no qual foram destacados discos do limbo foliar das porções basal, mediana e apical. A área foliar foi estimada através da área conhecida dos discos (ACD) foliares destacados, do peso dos discos foliares (PDF) e do peso total das folhas (PTF), tomados em balança analítica e de precisão Adventure AR2140 - 210g divisão de 0,0001g. Foi estimada a área foliar total aplicando-se a seguinte fórmula: AF = PTF x ACD / PDF; massa fresca e seca de raiz e parte aérea: a parte aérea foi separada das raízes com auxílio de tesoura, e cada parte foi pesada individualmente, determinando assim a massa fresca de parte aérea e de raiz. Em seguida, foram colocadas em sacos de papel devidamente identificados, e colocados em estufa a $65^{\circ} \mathrm{C}$ por 72 horas, pesando-se novamente para obter a massa seca.

Os resultados foram submetidos à análise de variância com auxílio do programa Sisvar (FERREIRA, 2011) e Teste de Tukey, ao nível de 5\% de probabilidade e análise de regressão para o período de avaliação.

\section{RESULTADOS E DISCUSSÃO}

Em relação à altura de plantas, observa-se na Tabela 1 que houve diferença significativa a partir do quadragésimo segundo dia após o transplante (DAT), sendo que a tela de sombreamento $30 \%$ (T2), tela de $50 \%$ (T3) e tela de manipulação de espectro de luz ChromatiNet ${ }^{\circledR}$ vermelha (T4) não diferenciaram entre si, bem como entre pleno sol (T1), T2 e T4. Aos 56, 70 e 84 DAT observa-se comportamento semelhante das médias, 
T2, T3 e T4 não diferenciaram entre si, bem como entre T1 e T4.

Analisando-se a Figura 1, observa-se tendência linear para todos os níveis de sombreamento em relação ao período de avaliação para altura de plantas, sendo que no decorrer das análises, T1 foi o que obteve menores médias, e, em contrapartida T2 e T3 foram os tratamentos com maiores médias.

Tabela 1. Altura de plantas (cm) de jatobá (Hymeneae courbaril L. var. Stilbocarpa) em diferentes níveis de sombreamento.

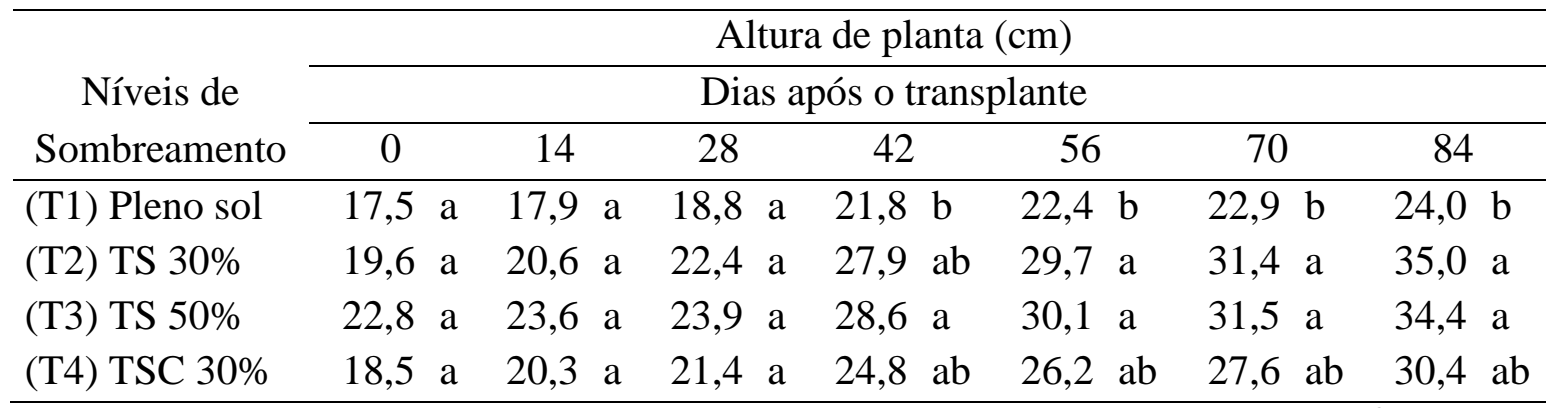

(TS = tela de sombreamento e TCV = tela de manipulação de espectro de luz ChromatiNet ${ }^{\circledR}$ vermelha). Médias seguidas de mesma letra minúscula na coluna não diferem entre si pelo teste de Tukey a $5 \%$ de probabilidade.

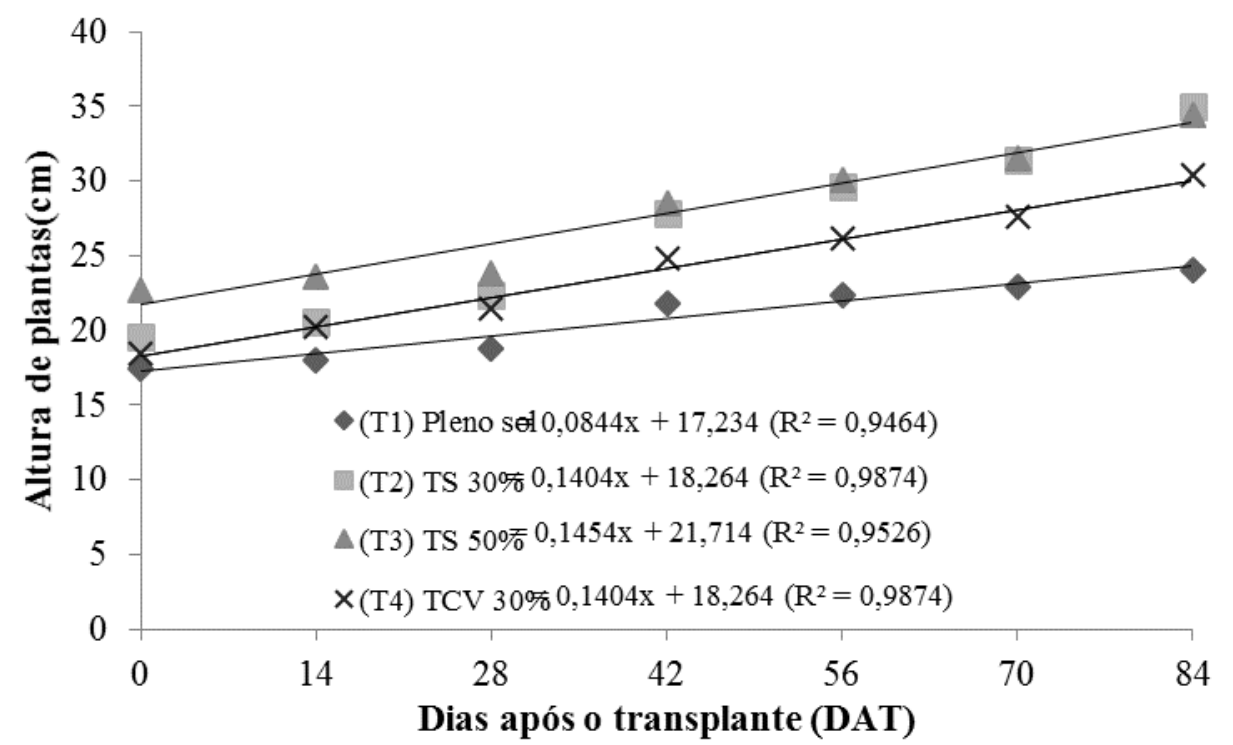

Figura 1. Altura de planta $(\mathrm{cm})$ de jatobá (Hymeneae courbaril L. var. Stilbocarpa) em diferentes níveis de sombreamento em relação ao período de avaliação (TS = tela de sombreamento e TCV = tela de manipulação de espectro de luz ChromatiNet ${ }^{\circledR}$ vermelha).

Em trabalho realizado por Lessa et al. (2010), os autores também observaram um maior crescimento de mudas de jatobá (Hymeneae courbaril L. var. Stilbocarpa) sob sombreamento de $50 \%$ em detrimento às mudas a pleno sol, corroborando com o presente trabalho. Em contrapartida, Campos e Uchida (2002) verificaram que as mudas de jatobá à pleno sol se desenvolveram mais quanto à altura do que aquelas submetidas ao sombreamento de 50\%, assim como resultados encontrados por Melo e Cunha (2008)

Cultura Agronômica, Ilha Solteira, v.26, n.3, p.330-346, 2017 
trabalhando com mudas de mulungu (Erythrina velutina), também pertencente à família Fabaceae, observaram que essas apresentaram maior altura de plantas quando submetidas também pleno sol, resultados opostos ao encontrado no presente trabalho.

O rápido crescimento em altura quando sombreada é um mecanismo de adaptação das plantas competitivas (GRIME, 1977) ou nômades (TINOCO; VASQUES-YANES, 1985). Há grande diversidade de respostas das espécies nativas a luminosidade, principalmente, quanto ao desenvolvimento vegetativo da parte aérea e a sobrevivência das mudas (SCALON; ALVARENGA, 1993). Os mesmos autores afirmam também que cada espécie florestal apresenta exigência luminosa própria para seu desenvolvimento, e algumas plântulas podem aproveitar e se desenvolver melhor em locais com alta intensidade luminosa e outras em sombreamento, existindo ainda aquelas espécies que são intermediárias.

A altura é uma ótima variável para se notar características de adaptações da planta às baixas luminosidades, pois espécies possuem diferentes padrões de respostas, de acordo com a sua capacidade adaptativa às variações na intensidade da luz (MUROYA et al., 1997). Por meio desta característica pode se analisar a qual estágio de sucessão pertence cada espécie. Segundo Lorenzi (1998), o jatobá (Hymeneae courbaril L. var. Stilbocarpa) pertence ao grupo de plantas oportunistas, que pela definição de Viana (1989) são espécies com sementes que não requerem clareiras para germinar, com plântulas que sobrevivem à sombra, mas que dependem de aberturas do dossel para atingir o estágio reprodutivo, o que explica as maiores alturas de muda, no presente trabalho, quando as mesmas são submetidas ao sombreamento.

Com relação às telas de manipulação de espectro de luz, a malha ChromatiNet $^{\circledR}$ vermelha tem a finalidade de alterar o espectro da luz, reduzindo as ondas azuis, verdes e amarelas e acrescentando as ondas na faixa espectral do vermelho e vermelho-distante, e nesse caso a luz vermelha tem influência no desenvolvimento das plantas, pelas alterações nas razões vermelho/vermelho distante (V:VD) absorvidas por formas interconversíveis do fitocromo (OLIVEIRA et al., 2008). Os mesmos autores afirmam que variações nas razões $\mathrm{V}: \mathrm{VD}$ estimulam respostas, como alongamento do caule, florescimento e alterações na condutância estomática. Segundo Lee (1987), as folhas transmitem e refletem pouca radiação entre os comprimentos de onda de 400-600nm, intervalo esse que segundo Kämpf (2005) compreende do violeta $(400-425 \mathrm{~nm})$ até parte do laranja $(585-640 \mathrm{~nm})$ excluindo o vermelho $(670-740 \mathrm{~nm})$. Portanto, no presente trabalho o ChromatiNet $^{\circledR}$ vermelho provavelmente não teve o efeito descrito por Oliveira et al. (2008), visto a qualidade de luz que a espécie em estudo necessita na fase avaliada. No entanto, Oren-Shamir et al. (2001) obtiveram mudas maiores de pau-de-incenso (Pittosporum variegatum) sob telado vermelho.

Na Tabela 2 observa-se que as médias de diâmetro de caule foram significativas estatisticamente a partir do quadragésimo segundo DAT. Nessa avaliação, aos 56 e 84

Cultura Agronômica, Ilha Solteira, v.26, n.3, p.330-346, 2017 
DAT T2 e T3 não se diferenciaram entre si, porém, se diferenciaram de T1 e T4.

A Figura 2 mostra a análise de regressão para o período de avaliação de todos os níveis de sombreamento para o diâmetro de caule, sendo que ao final das avaliações T1 obteve menores médias de diâmetro em relação aos demais tratamentos e que T2 e T3 obtiveram médias numericamente semelhantes.

Tabela 2. Diâmetro de caule (mm) de jatobá (Hymeneae courbaril L. var. Stilbocarpa) em diferentes níveis de sombreamento.

\begin{tabular}{|c|c|c|c|c|c|c|c|c|}
\hline \multirow{3}{*}{$\begin{array}{c}\text { Níveis de } \\
\text { Sombreamento }\end{array}$} & \multicolumn{8}{|c|}{ Diâmetro de caule (mm) } \\
\hline & \multicolumn{8}{|c|}{ Dias após o transplante } \\
\hline & 0 & 14 & 28 & & 42 & 56 & 70 & 84 \\
\hline (T1) Pleno sol & 3,35 a & 3,37 a & 3,58 & $\mathrm{a}$ & $3,63 \mathrm{~b}$ & $3,73 \mathrm{~b}$ & $3,83 \mathrm{~b}$ & $4,03 \mathrm{~b}$ \\
\hline (T2) TS 30\% & 3,44 a & 3,52 a & 3,53 & $\mathrm{a}$ & 3,84 a & 4,02 a & $4,19 \mathrm{ab}$ & $4,53 \mathrm{a}$ \\
\hline (T3) TS 50\% & 3,60 a & 3,70 a & 3,83 & $\mathrm{a}$ & $4,10 \mathrm{a}$ & $4,21 \mathrm{a}$ & 4,35 a & $4,61 \mathrm{a}$ \\
\hline (T4) TSC $30 \%$ & 3,33 a & 3,52 a & 3,45 & $\mathrm{a}$ & $3,74 \mathrm{~b}$ & $3,89 \mathrm{~b}$ & $4,05 \mathrm{~b}$ & $4,34 \mathrm{~b}$ \\
\hline
\end{tabular}

(TS = tela de sombreamento e TCV = tela de manipulação de espectro de luz ChromatiNet ${ }^{\circledR}$ vermelha). Médias seguidas de mesma letra minúscula na coluna não diferem entre si pelo teste de Tukey a 5\% de probabilidade.

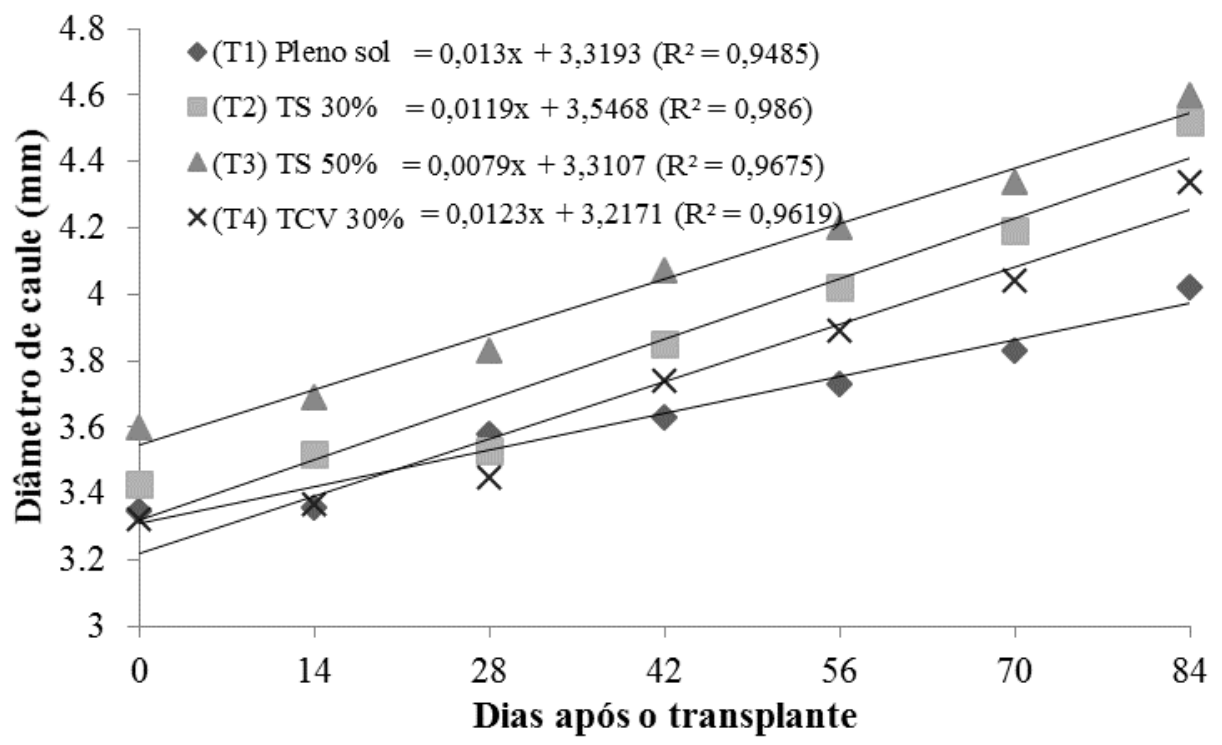

Figura 2. Diâmetro de caule (mm) de jatobá (Hymeneae courbaril L. var. Stilbocarpa) em diferentes níveis de sombreamento em relação ao período de avaliação (TS = tela de sombreamento e TCV = tela de manipulação de espectro de luz ChromatiNet ${ }^{\circledR}$ vermelha).

As médias do diâmetro de caule de mudas de mulungu (Erythrina velutina) obtidas por Melo e Cunha (2008) diferiram estatisticamente entre os tratamentos sendo que os níveis de $20 \%$ e $60 \%$ foram os que demonstraram os melhores resultados, da mesma forma que Engel e Poggiani (1990) constataram, também, um maior ganho em diâmetro para os níveis de $0 \%$ a $41 \%$ de sombra para as espécies imburana-de-cheiro (Amburana cearenses), ipê felpudo (Zeyhera tuberculosa), ipê roxo (Tabebuia avellanedae) e corticeira (Erythrina

Cultura Agronômica, Ilha Solteira, v.26, n.3, p.330-346, 2017 
speciosa), sendo que ambos resultados diferem do presente trabalho no qual as melhores médias de diâmetro de caule foram obtidas em níveis de sombreamento de 30 e $50 \%$. Em contrapartida, Almeida et al. (2005b) observaram maior ganho em diâmetro nos níveis de 30 e 50\% para o fedegoso (Cassia occidentalis) e em sol pleno para a acácia (Acacia cyanophylla). Os mesmos autores observaram ainda não haver diferença significativa no ganho em diâmetro em diferentes níveis de sombreamento para as espécies moreira (Luehea divaricata) e jatobá (Hymenaea courbaril).

Entretanto, Campos e Uchida (2002) não observaram diferença significativa entre os níveis de sombreamento e a pleno sol em mudas de jatobá (Hymenaea courbaril) da mesma forma que Varela e Santos (1992) observaram decréscimo no diâmetro de caule de mudas de angelim vermelho (Dinizia excelsa) cultivadas sob $70 \%$ de sombreamento. Entretanto, os níveis de sombreamento não influenciaram significativamente o diâmetro de caule das mudas de cedrorana (Cedrelinga catenaeformis).

Campos e Uchida (2002) confirmaram uma existência clara de superioridade de mudas de diâmetros mais espessos em relação às de menores espessuras. Os autores apontam uma forte correlação entre o diâmetro do colo com a sobrevivência, mas, sobretudo, com o ritmo de crescimento das mudas após o plantio.

Na relação entre altura de planta e diâmetro de caule mostrada na Tabela 3 observa-se que houve diferença estatística a partir dos 56 DAT, sendo que T2, T3 e T4 não se diferenciaram entre si da mesma forma que não houve diferença entre T1, T3 e T4. Aos 70 e 84 DAT, T1 e T4 não se diferenciaram entre si.

Tabela 3. Relação entre altura de plantas e diâmetro de caule de jatobá (Hymenaea courbaril L. var. Stilbocarpa) em diferentes níveis de sombreamento.

\begin{tabular}{|c|c|c|c|c|c|c|c|c|c|}
\hline \multirow{3}{*}{$\begin{array}{c}\text { Níveis de } \\
\text { Sombreamento }\end{array}$} & \multicolumn{9}{|c|}{$\mathrm{AP} / \mathrm{DC}$} \\
\hline & \multicolumn{9}{|c|}{ Dias após o transplante } \\
\hline & 0 & 14 & 28 & & 42 & & 56 & 70 & 84 \\
\hline (T1) Pleno sol & 5,14 a & 5,28 a & 5,22 & $\mathrm{a}$ & 5,93 & $\mathrm{a}$ & $5,94 \mathrm{~b}$ & $5,95 \mathrm{~b}$ & $5,98 \mathrm{~b}$ \\
\hline (T2) TS 30\% & 5,67 a & $5,84 \mathrm{a}$ & 6,30 & a & 7,12 & $\mathrm{a}$ & 7,23 a & 7,38 a & 7,80 a \\
\hline (T3) TS 50\% & 6,39 a & $6,42 \mathrm{a}$ & 6,27 & $\mathrm{a}$ & 7,05 & $\mathrm{a}$ & $7,16 \mathrm{ab}$ & 7,28 a & 7,54 a \\
\hline (T4) TSC $30 \%$ & 5,56 a & 6,03 a & 6,21 & $\mathrm{a}$ & 6,59 & $\mathrm{a}$ & $6,70 \mathrm{ab}$ & $6,83 \mathrm{ab}$ & $7,17 \mathrm{ab}$ \\
\hline
\end{tabular}

DMS 1,26

(TS = tela de sombreamento e TCV = tela de manipulação de espectro de luz ChromatiNet ${ }^{\circ}$ vermelha). Médias seguidas de mesma letra minúscula na coluna não diferem entre si pelo teste de Tukey a 5\% de probabilidade.

A Figura 3 mostra tendência linear para T1, T2 e T3 e tendência quadrática para T4 em relação aos tratamentos de níveis de sombreamento e o período de avaliação para a relação AP/DC, nesse caso aos 42 DAT, T4 superou as médias dos demais tratamentos decaindo posteriormente, sendo que aos 84 DAT, T2 e T3 obtiveram as maiores médias.

Cultura Agronômica, Ilha Solteira, v.26, n.3, p.330-346, 2017 


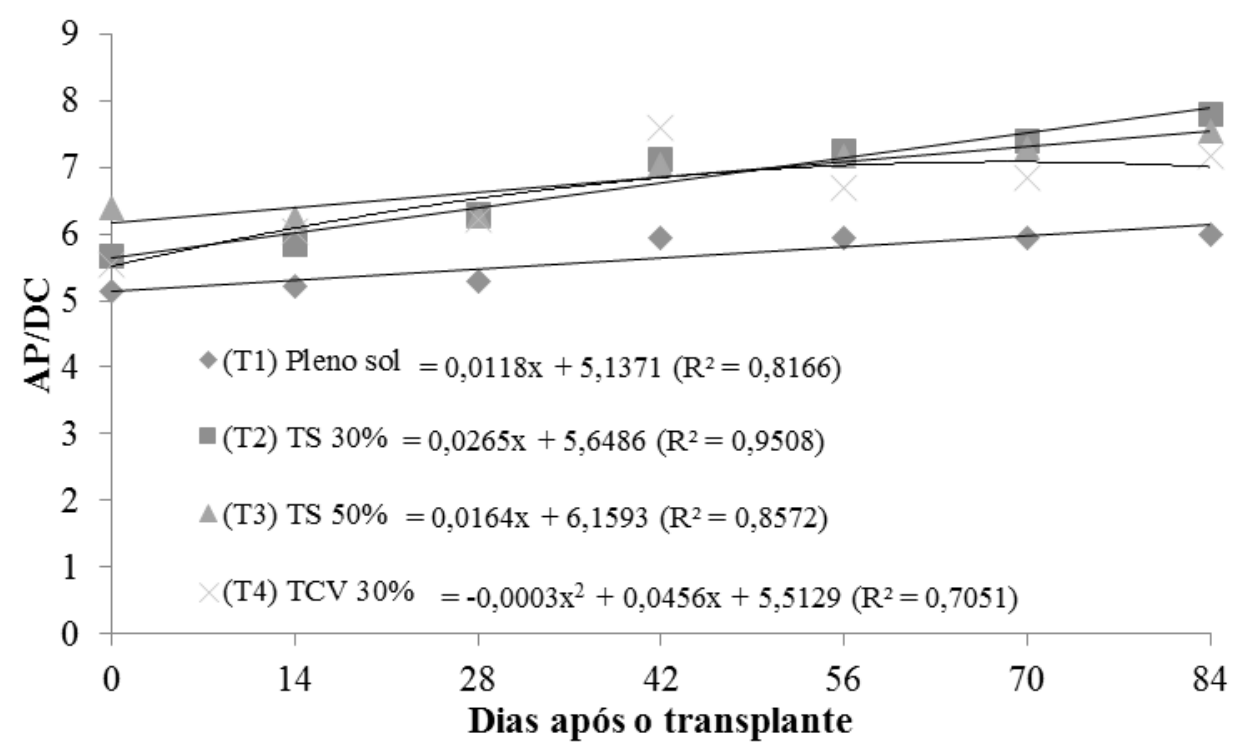

Figura 3. Relação entre altura de plantas e diâmetro de caule de jatobá (Hymenaea courbaril L. var. Stilbocarpa) em diferentes níveis de sombreamento em relação ao período de avaliação (TS = tela de sombreamento e TCV = tela de manipulação de espectro de luz ChromatiNet $\AA$ vermelha).

Lessa et al. (2010), Melo e Cunha (2008), Chaves e Paiva (2004) observaram maiores relações de AP/DC em relação aos níveis de sombreamento em detrimento ao tratamento à pleno sol em mudas de jatobá (Hymeneae courbaril), corroborando com o presente trabalho. Todavia, Campos e Uchida (2002) obtiveram relação AP/DC maiores em mudas da mesma espécie sem sombreamento, resultado que contradiz os autores citados assim como ao do presente trabalho.

Sturion e Antunes (2000) indicam que a relação altura/diâmetro de caule constitui um dos parâmetros usados para avaliar a qualidade de mudas florestais, pois, além de refletir o acumulo de reservas, assegura maior resistência e melhor fixação no solo. Trabalho realizado por Carneiro (1995) com mudas de pinus indica que uma boa relação altura/diâmetro para ser um bom índice deve ser obtido quando os valores estão entre 5,4 a 8,1 , e no presente trabalho em todos os níveis de sombreamento a relação AP/DC se encontra nesse intervalo.

No teor de clorofila das folhas (Tabela 4) observa-se que houve diferença estatística apenas a partir dos 42 DAT, sendo que T2, T3 e T4 se diferenciaram de T1, o menor teor de clorofila das folhas, resultados semelhantes encontrados aos 56 e 70 DAT. Aos 84 DAT tanto $\mathrm{T} 1$ quanto $\mathrm{T} 4$ obtiveram teores de clorofila estatisticamente menores em relação ao $\mathrm{T} 2$ e T3.

A Figura 4 apresenta a análise de regressão para todos os níveis de sombreamento para o teor de clorofila das folhas em relação ao período de avaliação. Até os 28 DAT os teores de clorofila são semelhantes em todos os níveis de sombreamento, a partir dos 42 DAT o teor de T1 continua constante, porém T2, T3 e T4 aumentam consideravelmente. 
Tabela 4. Teor de clorofila (mg $100 \mathrm{~cm}^{-2}$ ) de folhas de jatobá (Hymenaea courbaril L. var. Stilbocarpa) em diferentes níveis de sombreamento.

\begin{tabular}{|c|c|c|c|c|c|c|c|c|c|c|}
\hline \multirow{3}{*}{$\begin{array}{c}\text { Níveis de } \\
\text { Sombreamento }\end{array}$} & \multicolumn{10}{|c|}{ Teor de clorofila $\left(\mathrm{mg} 100 \mathrm{~cm}^{-2}\right)$} \\
\hline & \multicolumn{10}{|c|}{ Dias após o transplante } \\
\hline & 0 & & 14 & & 28 & & 42 & 56 & 70 & 84 \\
\hline (T1) Pleno sol & 2,01 & $\mathrm{a}$ & 1,58 & a & 1,58 & $\mathrm{a}$ & $2,19 \mathrm{c}$ & $1,84 \mathrm{c}$ & $1,38 \mathrm{c}$ & $0,88 \mathrm{c}$ \\
\hline (T2) TS $30 \%$ & 1,82 & $\mathrm{a}$ & 2,00 & a & 1,99 & $\mathrm{a}$ & $3,61 \mathrm{ab}$ & 3,14 a & $2,67 \mathrm{~b}$ & $1,72 \mathrm{a}$ \\
\hline (T3) TS 50\% & 2,26 & $\mathrm{a}$ & 1,75 & a & 1,84 & $\mathrm{a}$ & 3,90 a & $2,87 \mathrm{ab}$ & 3,38 a & $1,34 \mathrm{ab}$ \\
\hline (T4) TSC $30 \%$ & 2,10 & $\mathrm{a}$ & 1,70 & a & 1,52 & $\mathrm{a}$ & $3,40 \mathrm{~b}$ & $2,46 \mathrm{~b}$ & $2,93 \mathrm{ab}$ & $1,09 \mathrm{c}$ \\
\hline
\end{tabular}

(TS = tela de sombreamento e TCV = tela de manipulação de espectro de luz ChromatiNet ${ }^{\circledR}$ vermelha) Médias seguidas de mesma letra minúscula na coluna não diferem entre si pelo teste de Tukey a 5\% de probabilidade.

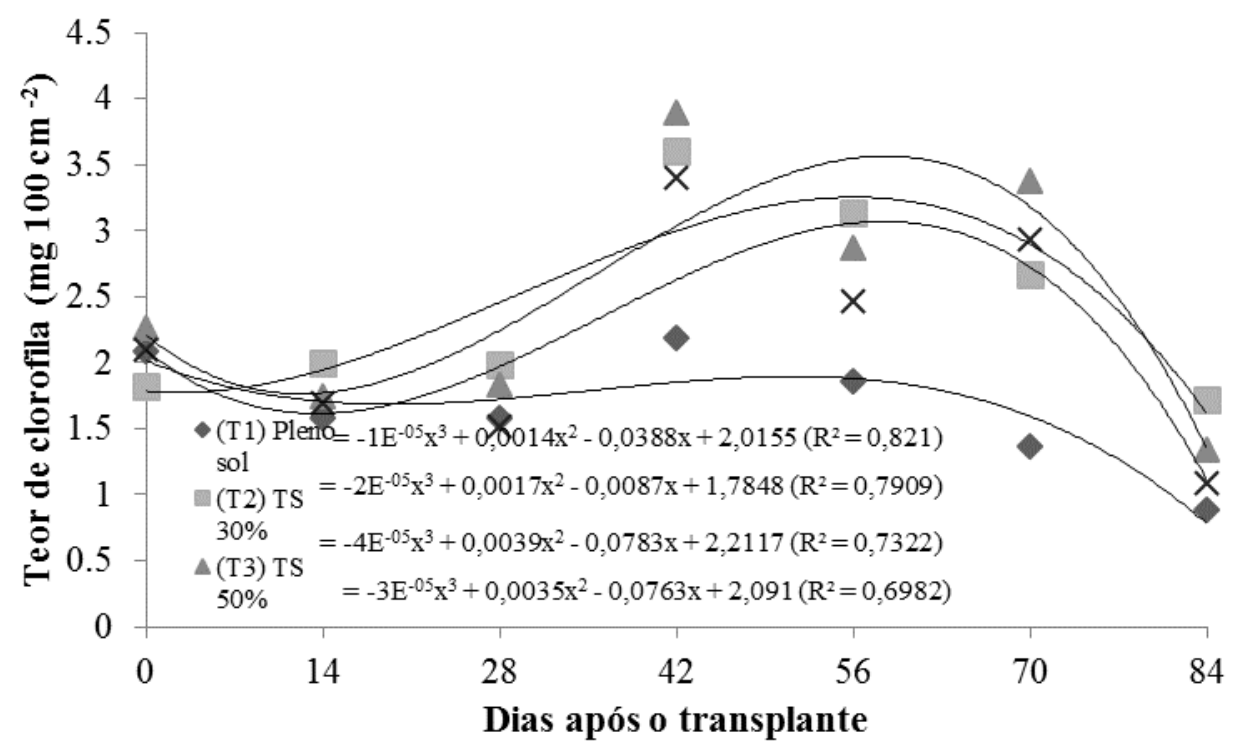

Figura 4. Teor de clorofila $\left(\mathrm{mg} 100 \mathrm{~cm}^{-2}\right.$ ) de folhas de jatobá (Hymenaea courbaril L. var. Stilbocarpa) em diferentes níveis de sombreamento em relação ao período de avaliação (TS = tela de sombreamento e TCV = tela de manipulação de espectro de luz ChromatiNet ${ }^{\circledR}$ vermelha).

Almeida et al. (2004) verificaram queda acentuada no teor de clorofila foliar total de canela-batalha (Cryptocaria aschersoniana) cultivadas a pleno sol, assim como Rego e Possamai (2006) em folhas de jequitibá-rosa (Cariniana legalis), dessa forma, a redução no teor de clorofilas das folhas a pleno sol (por unidade de área) é amplamente relatada na literatura, como registrado por Naves et al. (1994). Os mesmos autores afirmam que o maior acúmulo de clorofila em níveis mais sombreados pode ser devido a um efeito compensatório da espécie a menor quantidade de radiação disponível. Boardman (1977) reforça a ideia de que folhas cultivadas sob baixas intensidades de luz, apresentam maiores teores de clorofila por unidade de área. 
Martinazzo et al. (2007) mostraram que, os teores de clorofila total foram maiores significativamente para as mudas de pitanga (Eugenia uniflora) cultivadas sob $50 \%$ de sombreamento, ocorrendo queda acentuada nesse teor nas plantas acondicionadas a pleno sol. Almeida et al. (2004), em estudo do crescimento inicial de canela-fogo (Cryptacaria aschersoniana) encontrou os mesmos resultados, assim como Scalon et al. (2002) para mudas de mamorana (Bombacopsis glaba) afirmando que o maior acúmulo de clorofila em níveis mais sombreados pode ser devido ao efeito compensatório da espécie a menor quantidade de radiação disponível. Almeida et al. (2004), reforçam a ideia de que folhas cultivadas sob baixas intensidades de luz, apresentam maiores teores de clorofila por unidade de área.

Comparando-se as Tabelas 1 e 4 observa-se que os níveis de sombreamento com maiores teores de clorofila produziram mudas com maior altura, isso significa que pode ter havido maior taxa fotossintética produzindo mais energia aumentando a planta em tamanho (OLIVEIRA et al. 2008).

A Tabela 5, na qual constam as médias de área foliar, T2 e T3 obtiveram as melhores médias mas não se diferiram estatisticamente entre si, porém se diferenciaram de T1 e T4. Esse resultado pode ter ocorrido pelo fato da incidência de raios solares ser menor possibilitando o desenvolvimento das folhas, já que a perda de água é bem menor quando se tem pouca luz, no caso à pleno sol as plantas precisam se proteger de alguma forma como a redução da superfície de contato da luz evitando a perda de água.

Tabela 5. Área foliar (AF), massa fresca e seca de parte aérea (MFPA e MSPA) e massa fresca e seca de raiz (MFR e MSR) de mudas de jatobá (Hymenaea courbaril L. var. Stilbocarpa) aos 84 dias após o transplante em diferentes níveis de sombreamento.

\begin{tabular}{|c|c|c|c|c|c|}
\hline \multirow[b]{2}{*}{$\begin{array}{c}\text { Níveis de } \\
\text { Sombreamento }\end{array}$} & \multicolumn{3}{|c|}{ Massa fresca } & \multicolumn{2}{|c|}{ Massa seca } \\
\hline & $\mathrm{AF}$ & Parte aérea & Raiz & Parte aérea & Raiz \\
\hline (T1) Pleno sol & $22,31 b$ & $6,10 \mathrm{c}$ & $2,68 \mathrm{c}$ & $2,51 \mathrm{~b}$ & $0,81 \mathrm{~b}$ \\
\hline (T2) TS $30 \%$ & 35,49 a & $11,07 \mathrm{~b}$ & $5,74 \mathrm{~b}$ & $4,58 \mathrm{~b}$ & $1,97 \mathrm{ab}$ \\
\hline (T3) TS 50\% & 35,98 a & $21,64 \mathrm{a}$ & 11,38 a & $9,01 \mathrm{a}$ & 3,89 a \\
\hline (T4) TSC $30 \%$ & $25,55 \mathrm{ab}$ & $11,43 \mathrm{~b}$ & $5,83 \mathrm{~b}$ & $4,59 \mathrm{~b}$ & $1,70 \mathrm{ab}$ \\
\hline
\end{tabular}

(TS = tela de sombreamento e TCV = tela de manipulação de espectro de luz ChromatiNet ${ }^{\circledR}$ vermelha). Médias seguidas de mesma letra minúscula na coluna não diferem entre si pelo teste de Tukey a 5\% de probabilidade.

Campos e Uchida (2002) não observaram diferença estatística entre os tratamentos de sombreamento para área foliar de jatobá (Hymeneae courbaril); o mesmo foi encontrado por Ferreira et al. (1977) com jatobá-do-cerrado (Hymeneae stignocarpa), resultados opostos ao encontrado no presente trabalho. Em contrapartida, Muroya et al. (1997) obtiveram mudas de jacareúba (Calophyllum angulare) com maior área foliar com o aumento do sombreamento, semelhantemente ao obtido por Scalon et al. (2001) que trabalhando com mudas de pitangueira (Eugenia uniflora) verificaram área foliar maior nos tratamentos com sombreamento em relação ao tratamento à pleno sol; assim, ambos os resultados corroboram

Cultura Agronômica, Ilha Solteira, v.26, n.3, p.330-346, 2017 
com o presente trabalho.

A Tabela 5 apresenta os valores de massa fresca e seca de parte aérea e raiz aos 84 dias após o transplante, sendo que em relação à massa fresca de parte aérea e raiz observa-se que T3 diferenciou-se estatisticamente dos demais tratamentos.

Braun et al. (2007) observaram que com o aumento do sombreamento houve aumento da massa fresca de parte aérea e raiz de café conillon (Coffea canephora), e o mesmo resultado foi encontrado por Farias et al. (1995) que até o nível de $50 \%$ de sombreamento obtiveram maior massa fresca de parte aérea em mudas de guatambu (Balfourodendon riedelianum), mostrando que independente do hábito de crescimento da planta (arbóreas ou arbustiva) ocorrem resultados que corroboram com o presente trabalho. Em contrapartida, Dantas et al. (2011) trabalhando com níveis de sombreamento em mudas de catingueiraverdadeira (Caesalpinia pyramidalis), que também pertence à família Fabacea, obtiveram massa fresca de parte aérea e de raiz menores no tratamento de $50 \%$ se comparado à pleno sol, resultado oposto ao encontrado no presente trabalho.

Em relação às telas de mudanças de espectro de luz, Dajoz (2006) afirma que em floresta fechada a quantidade de luz nesse ambiente passa de 10.000 Lux sobre o dossel para 100 - 200 Lux ao nível do solo; como averiguado anteriormente por Viana (1989), o jatobá é uma planta oportunista, que não necessita de grande intensidade luminosa na germinação e desenvolvimento, ou seja, essa espécie provavelmente recebe uma quantidade de luminosidade entre 100 a 200 Lux. No presente trabalho observa-se que a tela de manipulação de espectro de luz ChromatiNet ${ }^{\circledR}$ vermelha, ultrapassou essa faixa produzindo mudas com menor área foliar e menor massa seca de parte aérea e raiz (Tabela 5). Em contrapartida, Henrique et al. (2011) verificaram maior incremento de massa seca de raiz e caule em mudas de cafeeiro (Coffea arabica) sob telado vermelho, resultado distinto ao do presente trabalho que mostra incremento de massa seca sob tela preta de $50 \%$ de sombreamento.

Observando as Tabelas 4 e 5, nota-se que o teor de clorofila foi maior nos níveis de 30 e 50\% de sombreamento, o mesmo acontecendo com a área foliar. Segundo Boardman (1977), a maior concentração de clorofila, tanto por unidade de massa quanto por unidade de área foliar em ambientes de baixa irradiância, pode indicar que o aumento no conteúdo de clorofila foi grande o suficiente para impedir a sua diluição ao longo de uma área foliar maior. Esse aumento na concentração de clorofilas pode representar maior investimento nos pigmentos responsáveis pela absorção da luz. Maior superfície foliar acarreta, muitas vezes, maior concentração de clorofila por unidade de área foliar, dessa forma esse efeito pode promover uma absorção de luz mais eficiente sob baixa intensidade de luz (Claussen, 1996).

Com relação à massa seca de parte aérea e raiz a Tabela 6 mostra que T3 obteve maior massa seca de parte aérea e raiz diferenciando-se estatisticamente dos demais níveis de sombreamento e à pleno sol.

Cultura Agronômica, Ilha Solteira, v.26, n.3, p.330-346, 2017 
Lima et al. (2010) também observaram incremento de matéria seca de parte aérea e raiz de mudas de jatobá quando houve aumento do nível de sombreamento, e o mesmo foi encontrado por Ramos et al. (2003) em mudas de jatobá-do-cerrado (Hymeneae stignocarpa); já Carvalho et al. (2006) obtiveram aumento de massa seca apenas de raiz para mudas sombreadas de licuri (Syagrus coronata) mostrando assim que corroboram com o presente trabalho. Porém, os mesmos autores encontraram, para massa seca de parte aérea, que os melhores resultados foram a pleno sol assim como Scalon et al. (2003) em mudas de castanha-do-maranhão (Bombacopsis glabra), Aguiar et al. (2011) em mudas de pau-brasil (Caesalpinia echinata) e Melo e Cunha (2008) em mudas de mulungu (Erythrina velutina).

\section{CONCLUSÃO}

Em relação ao nível de sombreamento as melhores mudas de jatobá são obtidas sob tela de sombreamento de 30 e $50 \%$ em até 84 dias após o transplante.

\section{AGRADECIMENTOS}

Ao técnico de laboratório José Hernandes Corrêa pela confecção dos telados de madeira.

\section{REFERÊNCIAS BIBLIOGRÁFICAS}

AGUIAR, F. F. A.; KANASHIRO, S.; TAVARES, A. R.; NASCIMENTO, T. D. R. dos; ROCCO, F. M. Crescimento de mudas de pau-brasil (Caesalpinia echinata Lam.), submetidas a cinco níveis de sombreamento. Revista Ceres, Viçosa, v. 58, n. 6, p.729-734, 2011 .

AlMEIDA, L. P.; AlVARENGA, A. A.; CASTRO, E. M.; ZANELA, S. M.; VIEIRA, C. V. Crescimento inicial de plantas de Cryptocaria aschersoniana Mez. submetidas a níveis de radiação solar. Ciência Rural, Santa Maria, v. 34, n. 1, p.83-88, 2004.

ALMEIDA, S. M. Z.; SOARES, A. M.; CASTRO, E. M.; VIEIRA, C. V.; GAJEGO, E. B. Alterações morfológicas e alocação de biomassa em plantas jovens de espécies florestais sob diferentes condições de sombreamento. Ciência Rural, Santa Maria, v. 35, n. 1, p.62$68,2005 a$.

ALMEIDA, S. Z. A.; SOARES, A. M.; VIEIRA, C. V.; GAJEGO, E. B. Alterações morfológicas e alocação de biomassa em plantas jovens de espécies florestais sob diferentes condições de sombreamento. Ciência Rural, Santa Maria, v. 35, n. 1, p.62-68, 2005 b.

BOARDMAN, N. K. Comparative photosynthesis of sun and shade plants. Annual Review of Plant Physiology, Palo Alto, v. 28, n. 4, p.355-377, 1977.

BRAUN, H.; ZONTA, J. H.; LIMA, J. S. S.; REIS, E. F. Produção de mudas de café

Cultura Agronômica, Ilha Solteira, v.26, n.3, p.330-346, 2017 
'conilon' propagadas vegetativamente em diferentes níveis de sombreamento. IDESIA, Arica, v. 25, n. 3, p.85-9185, 2007.

CAMPOS, M. A. A.; UCHIDA, T. Influência do sombreamento no crescimento de mudas de três espécies amazônicas. Pesquisa Agropecuária Brasileira, Brasília, v. 37, n. 3, p.281-288, 2002.

CARNEIRO, J. G. A. Produção e controle de qualidade de mudas florestais. Curitiba: UFPR/FUPEP, 1995. $451 \mathrm{p}$.

CARVALHO, N. O. S.; PELACANI, C. R.; RODRIGUES, M. O. S.; CREPALDI, I. C. Crescimento inicial de plantas de licuri (Syagrus coronata (Mart.) becc.) em diferentes níveis de luminosidade. Revista Árvaore, Viçosa, v. 30, n. 3, p.351-357, 2006.

CHAVES, A. S.; PAIVA, H. N. Influência de diferentes períodos de sombreamento sobre a qualidade de mudas de fedegoso (Senna macrantera (Collad.) Irwin et Barn.). Scientia Forestalis, Piracicaba, n. 65, p.22-29, 2004.

CLAUSSEN, J. W. Acclimation abilities of three tropical rainforest seedlings to an increase in light intensity. Forest Ecology and Management, Amsterdam, v. 80, n. 5, p.245-255, 1996.

DAJOZ, R. Princípios de ecologia. 7. ed. Porto Alegre: Artmed, 2006. 412 p.

DANTAS, B. F.; LOPES, A. P.; SILVA, F. F. S.; BATISTA, P. F.; PIRES, M. M. M. S.; ARAGÃO, C. A. Produção de mudas de catingueira-verdadeira (Caesalpinia pyramidalis Tul.) em função de substratos e luminosidades. Revista Científica, Jaboticabal, v. 39, n. $1 / 2$, p.34-43, 2011.

EMPRESA BRASILEIRA DE PESQUISA AGROPECUÁRIA - EMBRAPA. Sistema brasileiro de classificação de solos. 3.ed. Brasília: Embrapa, 2013. 353 p.

ENGEL, V. L.; POGGIANI, F. Influência do sombreamento sobre o crescimento de mudas de algumas essências nativas e suas implicações ecológicas e silviculturais. IPEF, Piracicaba, v. 10, n. 43/44, p.1-10, 1990.

FANTI, S. C.; PEREZ, S. C. J. G. A. Influência do sombreamento artificial e da adubação química na produção de mudas de Adenanthera pavonina L. Ciência Florestal, Santa Maria, v. 13, n. 1, p.49-56, 2003.

FARIAS, J. A. C.; OLIVEIRA, O. S.; FRANCO, E. T. H. Crescimento inicial do guatambu, Balfourodendon riedelianum (Engl.) Engl., em diferentes intensidades luminosas. Ciência Florestal, Santa Maria, v. 5, n. 1, p.69-86, 1995.

FERREIRA, D. F. SISVAR: a computer statistical analysis system. Ciência Agrotécnica, Lavras, v. 35, n. 6, p.1039-1042, 2011.

FERREIRA, M. G. M.; CÂNDIDO, J. F.; CANO, M. A. O.; CONDÉ, A. R. Efeito do sombreamento na produção de mudas de quatro espécies florestais nativas. Revista Árvore,

Cultura Agronômica, Ilha Solteira, v.26, n.3, p.330-346, 2017 
Viçosa, v. 1, n. 2, p.121-134, 1977.

FURLANI JUNIOR, E.; NAKAGAWA, J.; BULHÕES, L. J.; MOREIRA, J. A. A.; GRASSI FILHO, H. Correlação entre leituras de clorofila e níveis de nitrogênio aplicados em feijoeiro. Bragantia, Campinas, v. 55, n. 1, p.171-175, 1996.

GRIME, J. P. Evidence for the existence of three primary srategies in plants and its relevance to ecological and evolutionary theory. The American Naturalist, Chicago, v. 982, n. 3, p.1169-1194, 1977.

HENRIQUE, P. C.; ALVES, J. D.; DEUNER, S.; GOULART, P. F. P.; LIVRAMENTO, D. E. do. Aspectos fisiológicos do desenvolvimento de mudas de café cultivadas sob telas de diferentes colorações. Pesquisa Agopecuária Brasileira, Brasília, v. 46, n. 5, p.458-465, 2011.

HUERTAS, L. Control ambiental em el vivero. Horticultura Internacional, Terragona, n. esp. 01, p.77-84, 2006.

KÄMPF, A. N. Substratos. In:

Produção comercial de plantas ornamentais.

Guaíba: Agrolivros, 2005. 256 p.

KRAMER, P. J.; KOZLOWSKI, T. Fisiologia das árvores. Lisboa: Fundação Calouste Gulbenkian, 1972. 745 p.

LEE, D. W. The spectral distribution of radiation in two neotropical rainforests. Biotropica, Zurich, v. 19, n. 2, p.161-166, 1987.

LESSA, D. C.; ARAUJO, M. E. R.; MENDONÇA, A. P.; CARMO, W. A.; MATOS, S. S.; MELO, R. M. S. Caracterização biométrica de mudas de jatobá submetidas a diferentes substratos e níveis de sombreamento. In: CONGRESSO DE PESQUISA E INOVAÇÃO DA REDE NORTE NORDESTE DE EDUCAÇÃO TECNOLÓGICA, 5., 2010, Maceió. Anais... Maceió: IFAL, 2010. p. 01-08.

LIMA, A. L. S.; ZANELLA, F.; CASTRO, L. D. M. Crescimento de Hymenaea courbaril L. var. stilbocarpa (Hayne) Lee et Lang. e Enterolobium contortisiliquum (Vell.) Morong (Leguminosae) sob diferentes níveis de sombreamento. Acta Amazonica, Manaus, v. 40, n. 1, p. 43-48, 2010.

LORENZI, H. Árvores brasileiras: manual de identificação e cultivo de plantas arbóreas nativas do Brasil. Nova Odessa: Plantarum, 1998. v. 1, 367 p.

MACHADO, R. R. B.; MEUNIR, I. M. J.; SILVA, J. A. A.; CASTRO, A. A. J. F. Árvores nativas para a arborização de Teresina, Piaúi. Revista da Sociedade Brasileira de Arborização Urbana, Piracicaba, v. 1, n. 1, p.10-18, 2006.

MARTINAZZO, E. G.; ANESE, S.; WANDSCHEER, A. C. D.; PASTORINI, L. H. Efeito do Sombreamento sobre o Crescimento Inicial e Teor de Clorofila Foliar de Eugenia uniflora Linn (Pitanga) - Família Myrtaceae. Revista Brasileira de Biociência, Porto Alegre, v. 5, n. 2, p.162-164, 2007.

Cultura Agronômica, Ilha Solteira, v.26, n.3, p.330-346, 2017 
MELO, R. R.; CUNHA, M. C. L. Crescimento inicial de mudas de mulungu (Erythrina velutina Wild.) sob diferentes níveis de luminosidade. Ambiência, Guarapuava, v. 4, n. 1, p.67-77, 2008.

MIELKE, M. S. Comparação de métodos de laboratório e de campo para estimativa da área foliar em fruteiras silvestres. Scientia Agricola, Piracicaba, v. 52, n. 1, p.82-88, 1995.

MUROYA, K.; VARELA, V. P.; CAMPOS, M. A. A. Análise de crescimento demudas de jacareúba (Calophyllum angulare - Guttiferae) cultivadas em condições de viveiro. Acta Amazônica, Manaus, v. 27, n. 3, p.197-212, 1997.

NAVES, V. L.; ALVARENGA, A. A.; OLIVEIRA, L. E. M. Comportamento estomático de mudas de três espécies florestais submetidas à diferentes níveis de radiação fotossintéticamente ativa. Ciência e Prática, Lavras, v.18, n. 4, p.408-414, 1994.

OLIVEIRA, E. C.; PIÑA-RODRIGUES, F. C. M.; FIGLIOLIA, M. B. Propostas para a padronização de metodologias em análise de sementes florestais. Revista Brasileira de Sementes, Londrina, v. 11, n. 1-3, p.1-42, 1989.

OLIVEIRA, J. R.; PAUlO, M. W.; CORRÊA, R. M.; REIS, E. S.; CARVALHO, M. A.; RODRIGUES, L. E.; REIS, M. M. Cultivos agrícolas utilizando telas coloridas e termorefletoras. In: JORNADA CIENTÍFICA, 1., 2008, Bambuí. Anais... Bambuí: CEFET, 2008 .

http://www.cefetbambui.edu.br/str/artigos_aprovados/Ci\%C3\%AAncias\%20Agrarias/34PT-6.pdf . .Acesso em: 20 dez. 2011.

OREN-SHAMIR, M.; GUSSAKOVSKY, E. E.; SHPIEGEL, E.; NISSIM-LEVI, A.; RATNER, K.; OVADIA, R.; GILLER, Y. E.; SHAHAK, Y. Coloured shade nets can improve the yield and quality of green decorative branches of Pittosporum variegatum. Journal of Horticultural Science and Biotechnology, Londres, v. 76, n. 2, p.353-361, 2001.

PAGLIARINI, M. K.; CASTILHO, R. M. M.; MARIANO-NASSER, F. A. C.; ALVES, M. C. Tratamentos pré-germinativos e substratos na germinação de sementes e biometria de plântulas de Hymenaea courbaril L. var. Stilbocarpa. Cultura Agronômica, Ilha Solteira, v. 25, n. 1, p.39-54, 2016.

POLYSACK INDÚSTRIAS. ChromatiNet Vermelha. São Paulo: Leme, 2011. Disponível em: http://www.polysack.com.br. Acesso em: 12 out. 2011.

RAMOS, K. M. O.; FELFILI, J. M.; SOUSA-SILVA, J. C.; FAGG, C. W.; FRANCO, A. C. Desenvolvimento inicial de plântulas de Hymenaea stigonocarpa Mart. ex. hayne, sob diferentes condições de sombreamento. Braflo, Campinas, v. 23, n. 77, p.37-42, 2003.

REGO, G. M.; POSSAMAI, E. Efeito de sombreamento sobre o teor de clorofila e crescimento inicial de Jequitibá-rosa. Boletim Pesquisa Florestal, Piracicaba, v. 53, n. 4, p. 179-194, 2006.

Cultura Agronômica, Ilha Solteira, v.26, n.3, p.330-346, 2017 
SCALON, S. P. Q.; ALVARENGA, A. A. Efeito do sombreamento sobre a formação de mudas de paupereira (Platycyamus regnelli Benth.). Revista Árvore, Viçosa, v. 17, n. 3, p.265-270, 1993.

SCALON, S. P. Q.; MUSSURY, R. M.; ROGONI, M. R.; SCALON FILHO, H. Crescimento inicial de mudas de Bombacopsis glabra (Pasq.) A. Robyns sob condição de sombreamento. Revista Árvore, Viçosa, v. 27, n. 6, p.753-758, 2003.

SCALON, S. P. Q.; SCALON FILHO, H.; RIGONI, M. R.; VERALDO, F. Crescimento inicial de mudas de espécies florestais nativas sob diferentes níveis de sombreamento. Revista Árvore, Viçosa, v. 26, n. 1, p.1-5, 2002.

SCALON, S. P. Q; SCALON FILHO, H.; RIGONI, M. R.; VERALDO, F. Germinação e crescimento de mudas de pitangueira (Eugenia uniflora L.) sob condições de sombreamento. Revista Brasileira de Fruticultura, Jaboticabal, v. 23, n. 3, p.652-655, 2001.

STURION; J. A.; ANTUNES, B. M. A. Produção de mudas de espécies florestais. In: GALVÃO, A. P. M. (Org.). Reflorestamento de propriedades rurais para fins de produtivos e ambientais. Colombo: Embrapa, 2000. cap. 7, p. 125-150.

TIGRE, C. B. Estudo de silvicultura especializada do nordeste. Mossoró: ESAM, 1976. $180 \mathrm{p}$.

TINOCO, C.; VASQUEZ-YANES, C. Diferencias en poblaciones de Piper hispidus hajo condiciones de luz contratante en uma selva alta perenifolia. In: GOMEZ-POMPA, A.; AMO, R.S. (Ed.). Investigaciones sobre la regeneration de selvas altas em Vera Cruz. Mexico: Alhambra Mexicana, 1985. p. 267-281.

VARELA, V. P.; SANTOS, J. Influência do sombreamento na produção de mudas de angelim pedra (Dinizia excelsa Ducke). Acta Amazonica, Manaus, v. 22, n. 3, p.407-411, 1992.

VIANA, V. M. Seed dispersal and gap regeneration: the case of three Amazonia tree species. 1989. 105 f. Tese (Doutorado em Biologia) - Harvard University, Cambridge, 1989.

Cultura Agronômica, Ilha Solteira, v.26, n.3, p.330-346, 2017 